
\title{
Polymer Substrates
}

Photovoltaic Manufacturing

OSTI Technology Monolithic Amorphous Silicon Modules on Continuous

\section{Annual Technical Progress Report, 5 July 1996-31 December 1997}

F. Jeffrey

Iowa Thin Film Technologies, Inc. Ames, Iowa

DISTABUTION OF THIS DOCUMENT IS UMLLMTED
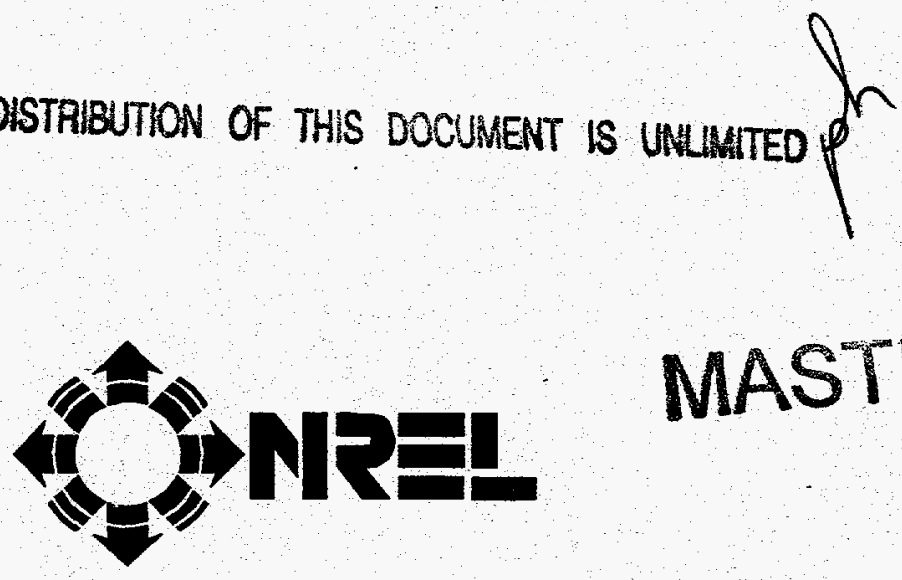

MASTER

National Renewable Energy Laboratory 1617 Cole Boulevard Golden, Colorado 80401-3393 A national laboratory of the U.S. Department of Energy Managed by Midwest Research Institute for the U.S. Department of Energy under Contract No. DE-AC36-83CH10093 


\section{DISCLAIMER}

Portions of this document may be illegible electronic image products. Images are produced from the best available original document. 


\section{Photovoltaic Manufacturing Technology Monolithic Amorphous Silicon Modules on Continuous Polymer Substrates}

\section{Annual Technical Progress Report,} 5.July 1996-31 December 1997

F. Jeffrey

Iowa Thin Film Technologies, Inc. Ames, Iowa

NREL technical monitor: R. Mitchell

National Renewable Energy Laboratory 1617 Cole Boulevard Golden, Colorado 80401-3393 A national laboratory of the U.S. Department of Energy Managed by Midwest Research Institute for the U.S. Department of Energy under Contract No. DE-AC36-83CH10093

Prepared under Subcontract No. ZAF-5-14271-4 August 1998 
This publication was reproduced from the best available camera-ready copy submitted by the subcontractor and received no editorial review at NREL.

\section{NOTICE}

This report was prepared as an account of work sponsored by an agency of the United States govemment. Neither the United States govemment nor any agency thereof, nor any of their employees, makes any warranty, express or implied, or assumes any legal liability or responsibility for the accuracy, completeness. or usefulness of any information, apparatus, product, or process disclosed, or represents that its use would not infringe privately owned rights. Reference herein to any specific commercial product, process, or service by trade name, trademark, manufacturer, or otherwise does not necessarily consitute or imply its endorsement, recommendation, or favoring by the United States government or any agency thereof. The views and opinions of authors expressed herein do not necessarily state or reflect those of the United States govemment or any agency thereof.

Available to DOE and DOE contractors from:

Office of Scientific and Technical Information (OSTI)

P.O. Box 62

Oak Ridge, TN 37831

Prices available by calling (423) $576-8401$

Available to the public from:

National Technical Information Service (NTIS)

U.S. Department of Commerce

5285 Port Royal Road

Springfield, VA 22161

(703) $487-4650$ 
TABLE OF CONTENTS .....................................................................................

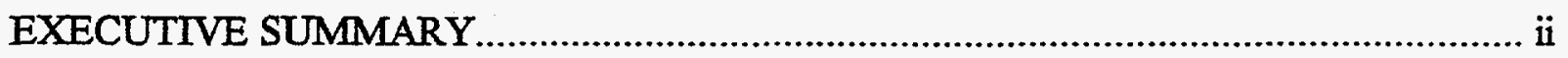

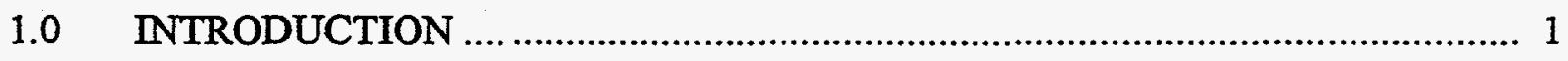

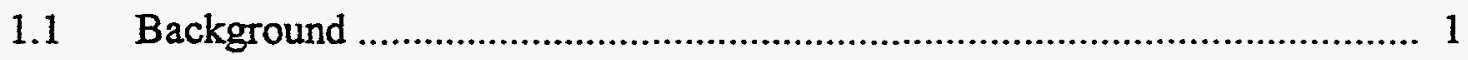

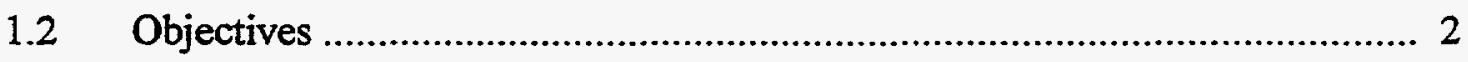

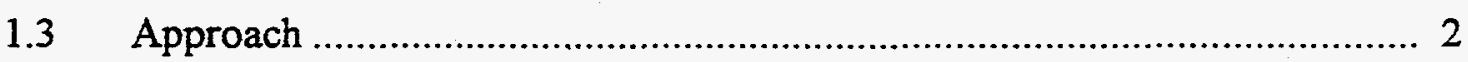

2.0 PHASE II ACTIVITIES AND ACCOMPLISHMENTS ….............................. 3

2.1 Task 5: Improved Metalization and $\mathrm{ZnO}$ Throughput.............................. 3

2.2 Task 6. Improvements in Laser-Scribing, Welding, and Printing Process Throughput ............................................................................. 7

2.3 Task 7. Substrate and Materials Cost Reduction ...................................... 8

2.4 Task 8: Busbar Attachment and Web Cutting Automation ........................ 9

2.5 Task 9: Reduction in Encapsulant and Module Assembly Costs ................ 11

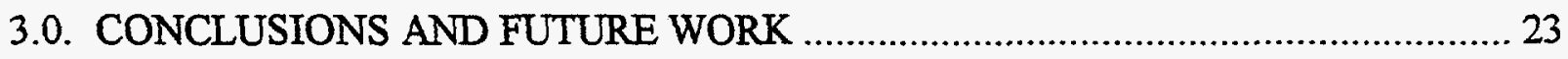




\section{Executive Summary}

Iowa Thin Film Technologies, Inc.'s (ITF) goal is to develop the most cost effective PV manufacturing process possible. To this end we have chosen a roll based manufacturing process with continuous deposition and monolithic integration. Work under this program is designed to meet this goal by improving manufacturing throughput and performance of the manufactured devices.

Significant progress was made during Phase II of this program on a number of fronts.

A new single pass tandem deposition machine was brought on line which allows greatly increased and improved throughput for rolls of tandem material.

The TCO deposition process was improved resulting in an increase in throughput by $20 \%$.

A new alignment method was implemented on the printing process which improves throughput six fold while improving alignment from $100 \mu \mathrm{m}$ to $10 \mu \mathrm{m}$.

A roll based lamination procedure was developed and implemented on selected products which improves throughput from $20 \mathrm{sq}$. ft./ hr. to $240 \mathrm{sq}$. ft. $/ \mathrm{hr}$.

A wide range of lower cost encapsulants were evaluated. A promising material was selected initially to be introduced in 5 year lifetime type products.

The sum of these improvements bring the overall cost reduction resulting from this program to $49 \%$. 


\subsection{INTRODUCTION}

The following ANNUAL TECHNICAL PROGRESS REPORT has been prepared under Subcontract ZAF-5-14271-04 9 (Mod No. 3) with the Midwest Research Institute National Renewable Energy Laboratory Division. This Phase II/ year two annual report covers the performance period of July 5, 1996 through December 31, 1997.

\section{$1.1 \quad$ Background}

The Department of Energy (DOE), in cooperation with the U.S. photovoltaic (PV) industry, has the goal of enhancing the U.S. PV industry leadership in the world market. To further this goal, the Photovoltaic Manufacturing Technology (PVMaT) project was initiated in FY 1991 to assist U.S. industry in the improvement in module manufacturing processes and the substantial reduction of module manufacturing cost. PVMaT's partnership with industry is being implemented in phased procurements to support continued progress as each phase accomplishes its objectives. Phases 1, 2, and 3 have been successfully implemented beginning with Phase 1 in 1991.

Phase 4A, the PVMaT addressed in this subcontract, addresses areas of research and development including issues related to cost-effective PV end-products, including module manufacturing, flexible manufacturing approaches, systems integration, and balance of systems. This subcontract represents an R\&D in approach under Phase 4A2, Product Driven PV Module Manufacturing Technology, and is planned as a three year effort. It is directed toward R\&D on PV module manufacturing process technology (with no funding for acquisition of production line equipment).

During this Phase 4A2 subcontract, Iowa Thin Film Technologies, Inc. (ITF) is to focus on increasing the throughput of their metalization, a-Si deposition, laser-scribing and welding . processes and on reducing the overall module manufacturing costs on the ITF production line by $68 \%$. Efforts to accomplish these goals will be focused on replacing the ITF TiN layer with a less absorbing layer $\mathrm{ZnO}$ layer; investigating alternate sources for the supply of $\mathrm{Zn}$ and $\mathrm{O}$ in the $\mathrm{ZnO}$ growth process; designing and implementing a web steering system machine control programs; identifying new laser operating parameters to optimize the laser beam scan speed and study alternative processes for the scribing; developing a new water-based insulating ink printing and roll based laminating processes for the ITF production line; designing and implementing baffles 
for the isolation of deposition regions; studying alternative methods of welding shunts in cellinterconnects; and automating the final process steps of busbar attachment and web cutting.

\subsection{Objectives}

The objective of this subcontract over its three year duration is to improve overall module performance, increase the throughput of the metalization, a-Si deposition, laser-scribing, and welding processes and to reduce the overall module manufacturing costs of the ITF production line by $68 \%$ from baseline.

The Phase $\amalg /$ year two task efforts were to continue with efforts begun in Phase I and were focused on task efforts described below. Accomplishment of these task efforts are expected to result in an overall reduction in cost of module manufacturing for the ITF module production line of $15 \%$ from baseline (including the efficiency improvements from Task 1.) This is to bring the total reduction to $49 \%$ for Phases I and II combined.

\subsection{Approach}

Phase II of the three subcontract phases began in July 1996 and continued through December 31 , 1997. Phase $\mathrm{I} /$ year two project activities focused on task efforts which included: increasing the throughput of the metalization, a-Si deposition, laser-scribing and printing processes; design and implementation of baffles for the isolation of metal deposition regions; investigation of the limits on the $\mathrm{ZnO}$ deposition rate; development of new machine control programs; identifying new laser operating parameters to optimize the laser beam scan speed; integrating a new, water based insulating ink into the pattern process; and automate the final process steps of busbar attachment and web cutting. The Phase II/ year two activities were divided into five tasks :

Task 5: Improved Metalization and $\mathrm{ZnO}$ Throughput

Task 6: Improvements in Laser-Scribing, Welding, and Printing Process Throughput

Task 7: Substrate and Materials Cost Reduction

Task 8: Busbar Attachment and Web Cutting Automation

Task 9: Reduction in Encapsulant and Module Assembly Costs

Phase II activities and accomplishments are described below organized under the five tasks. 


\subsection{PHASE II ACTIVITIES AND ACCOMPLISHMENTS}

\subsection{Task 5: Improved Metalization and $\mathrm{ZnO}$ Throughput}

Phase II Task 5 efforts were aimed at increasing the throughput of the metalization and roll-toroll $\mathrm{ZnO}$ deposition systems. The ITF design and implementation of an isolation baffle system for the isolation of deposition regions in the metalization system was expected to result in a $15 \%$ overall cost reduction in $\$ / W$ from baseline. This task effort was expected to result in a new operating regimen for the $\mathrm{ZnO}$ system, including a number of design modifications.

Task 5 activities focused on completion of the metalization baffle; establishing rate bases for all layers in the tandem deposition machine; demonstrate deposition of $\mathrm{ZnO}$ at $6 \mathrm{in} / \mathrm{min}$ with a sheet resistivity of $<10 \mathrm{ohms} / \mathrm{sq}$.; demonstrating operation of the metalization system functioning in one pass; and determining parameter dependence of $\mathrm{ZnO}$ deposition on temperature and $\mathrm{DEZ}$ flow.

\section{Metalization baffle}

Constraints on the baffle system design were developed based on experience with the earlier system and device runs. The most significant conclusions on constraints are as follow:

a) web entrance and exit openings between top and bottom parts of the chamber need to be approximately 1 in. long and approaching 30 mils in gap width;

b) All baffle joints should overlap by at least 0.5 in. to minimize diffusion rates;

c) the web cannot contact or slide on a fixed surface-meaning rollers are needed at web transfer slits;

d) the pressure in the web outgas region needs to be reduced to the 10 to 20 mTorr range from the current 70 mTorr value.

The overall layout of the baffles in the chamber is shown in Figure 1. Assembly drawing details of the critical web transfer openings are shown in Figure 2.

\section{Tandem deposition machine}

A variability was observed in material quality from the metalization system. This problem was tracked down to variations in the amount of water in the incoming polyimide web and therefore required different requirements for the maximum speed of the bakeout process. Slowing the web down to the speed required for bakeout limits the throughput for the sputtering process. It was determined that a low cost chamber could be fabricated for bakeout and thus allow the more expensive sputtering process to operate at optimum speed. The overall cost of this arrangement was determined to be lower. Such a bakeout chamber will be fabricated during the next year.

The new single pass tandem machine was brought on line during this phase. Deposition rates and uniformities were optimized for each of the six deposition zones independently and then jointly for 
Upper Oven Baffle 20 Gauge All

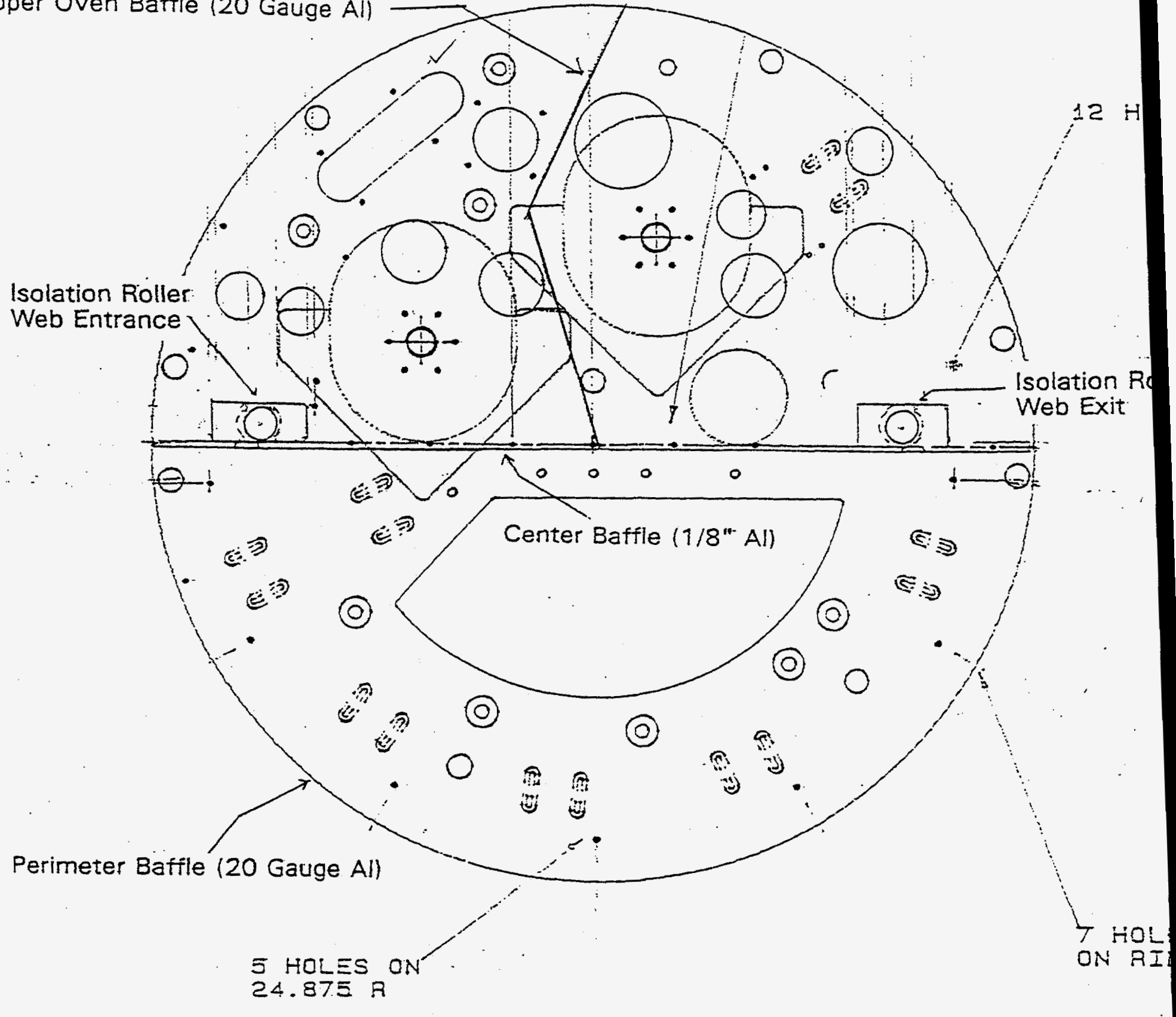

Figure 1. Drawing of The metalization system bearing plates with positions of baffles for isolating the outgas region, the metal sputtering region, and the reactive sputtering region. 

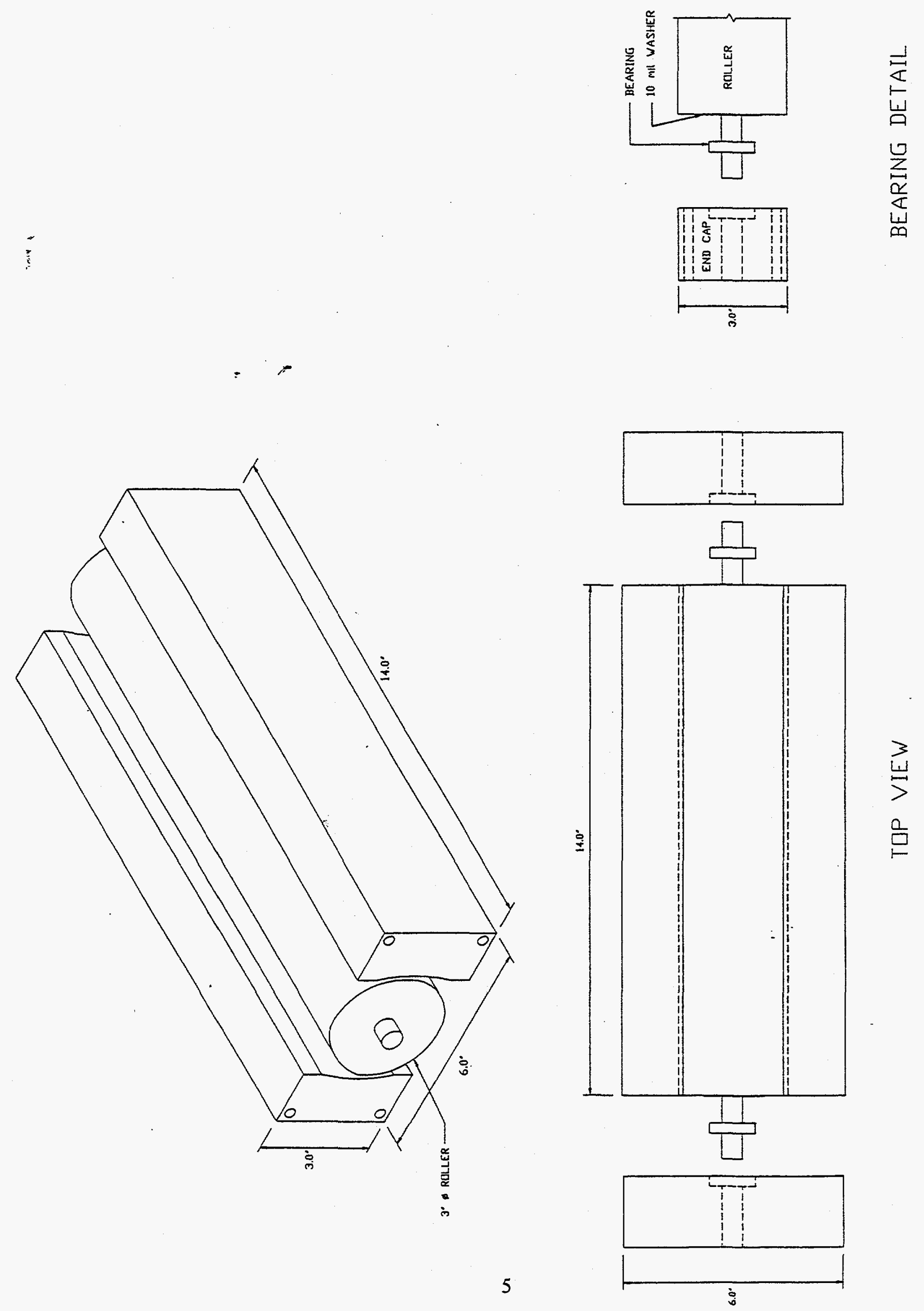

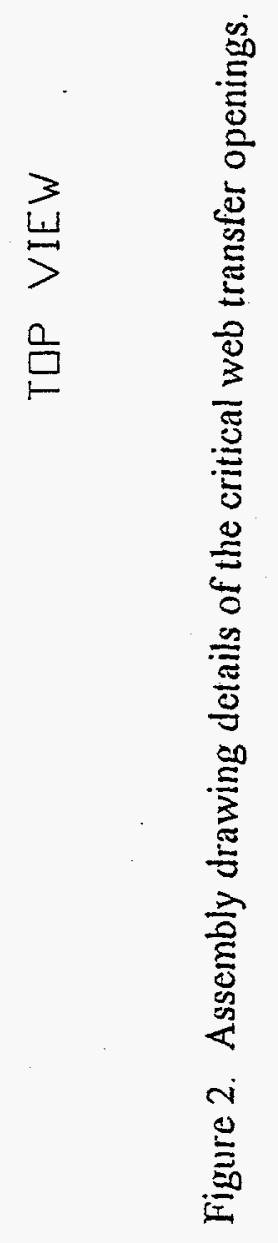


a complete tandem device. Currents and fill factors are slightly better than for tandem devices made by passing a web through the single junction machine twice. This might be expected because there is no air exposure between the two device depositions. However, device voltage is lower than it was from the previous system. Voc also dropped during the run. Part of the effect was determined to be thermal control of the $\mathrm{p}+$ deposition boxes. Extra cooling was installed resulting in higher Voc which is stable during the runs. The voltage is still slightly low. The causes of this are still under investigation.

Other than the Voc problem, the tandem system operates smoothly and uniformly.

\section{Improvement in $\mathrm{ZnO}$ deposition rate}

Insulator ink baked out at $200 \mathrm{C}$ has become the normal operating parameter prior to the $\mathrm{ZnO}$ deposition. This is to prevent the ink from outgassing during the $\mathrm{CVD} \mathrm{ZnO}$ process. Although the ink bake out allows for higher $\mathrm{ZnO}$ deposition temperatures, we are awaiting further testing before permanently changing this parameter.

A new gas distribution plate has been installed in the $\mathrm{ZnO}$ deposition chamber to aid in producing a more homogeneous material. The results from this test show that the zinc oxide deposition produces good material. However, it may possibly be thinner then normal along one edge. Analysis of this material is continuing.

A second test of the small $\mathrm{O} 2$ clean box is also scheduled.

These additions are steps toward accomplishment of the goal of a single pass $\mathrm{ZnO}$ deposition at an increased web rate.

\section{Dependence of $\mathrm{ZnO}$ deposition on temperature and DEZ flow}

Parameters which have been recognized as affecting the deposition of the zinc oxide, $\mathrm{ZnO}$, and transparent conducting oxide are: $\mathrm{H}_{2} \mathrm{O}$ and $\mathrm{DEZ}$ carrier gas flow rates, $\mathrm{H}_{2} \mathrm{O}$ and $\mathrm{DEZ}$ bubbler temperatures, and deposition zone temperature and pressure.

It was found that by increasing the DEZ carrier gas flow rate, the deposition rate decreased. This decrease was a result of the argon carrier gas flows acting as a diluent and the reaction being water starved. To minimize the diluent effect of the carrier gas, the flow should be kept at a suitable minimum. However, as this would reduce the reactant flow rate, the bubbler temperatures would need to be raised to increase the partial pressure in order to maintain a. constant molar flow rate of the respective species. Because of the hazards associated with DEZ at elevated temperatures, the DEZ carrier gas flow rate and bubbler temperature were fixed for these tests. The bubbler temperature and flow rate of the water was varied. It has been found that at the optimum water bubbler temperature and argon carrier gas flow rate, there was an increase in $\mathrm{ZnO}$ deposition of up to $27 \%$ over current standard operating parameters. 
There was not a great dependence of pressure on the deposition rate. At significantly higher or lower pressures there was some decrease in $\mathrm{ZnO}$ deposition rate and current operating parameters are near the optimum.

It was known previously that a higher temperature during deposition improves the $\mathrm{ZnO}$. However, because of incompatibilities with the insulator ink, this process has been kept at a lower temperature. Now, with improvements in the ink and printing process, it may be possible to increase the temperature of the $\mathrm{ZnO}$ deposition. It has been found that with an increase in temperature of approximately $15 \mathrm{C}$, there is an increase in deposition rate of up to $20 \%$ over current operating parameters.

\subsection{Task 6: Improvements in Laser-Scribing, Welding, and Printing Process Throughput}

Phase II Task 6 efforts were aimed at implementing and evaluating hardware changes in the alignment systems which appeared beneficial based on related Phase I results. Wide field of view sensors selection and implementation, redesign of laser and printer platens, and development of new machine control programs integrating the new detectors and hardware improvements were aimed at reduction of throughput time in both the laser-scribing, welding and printing processes. Work under this task in conjunction with Tasks 2 and 11, were expected to reduce the overall $\$ / W$ cost of module manufacturing for the laser and printer process steps by $17 \%$ from baseline.

Task activities were undertaken to complete the choice of alignment system hardware modifications; demonstrate the operation of web alignment and scribing at $2 \mathrm{~min} / \mathrm{frame}$; complete the evaluation and design of the web tracking method; and demonstrate control of tracking by web steering.

\section{Alignment system hardware modifications}

Integration of drive motors, controllers and computer subsystems into the new printer system was completed as was work on software development. Full alignment tests on actual web were conducted with the new printer and web alignment reproducibility was \pm 10 microns.

Tests of new printer/screen alignment system indicates a five fold improvement in printer throughput (to 200 frames $/ \mathrm{hr}$.) with a seven-fold improvement in alignment accuracy (to less than 2 mil resolution).

\section{Printer tracking by web steering}

After evaluating accuracy and cost of the alternatives, side to side tracking by web steering was replaced by alignment of the printing screen to the scribed pattern on the web. Alignment of printed pattern to the scribed pattern has a resolution of $\pm 10 \mu \mathrm{m}$ and a reproducibility of \pm 25 $\mu \mathrm{m}$. The screen alignment equipment has $\mathrm{x}, \mathrm{y}, \theta$ adjustment, screen lift-up during web transport, and anti-lash spring tensioning of the screen motion. Registration mark detection is done with precision scribe-line sensors 


\subsection{Task 7: Substrate and Materials Cost Reduction}

Phase II Task 7 efforts were aimed at integrating a new, water based insulating ink into the patterning process to replace the current organic solvent emissions. The critical evaluation of candidates for this ink included the correct laser beam absorption properties, vaporization characteristics, low outgassing, the ability to provide an adequate laser beam stop for the TCO cut with a single print, and ink adhesion durability.

Task efforts were to complete initial module tests of best candidate inks; complete selection of optimum ink based on testing; demonstrate module fabrication using new ink; and demonstrate adequacy of ink using single print.

\section{$\underline{\text { Ink }}$}

A two part epoxy ink (with catalyst) is now the standard insulator ink. It dries fast, exhibits low outgassing for $\mathrm{ZnO}$ deposition, but creates waste with unusable ink and containers.

A one-part epoxy (no catalyst) ink dries fast, has low outgassing; is reusable, but dries more slowly than the two-part epoxy ink. New ovens using forced air drying, rather than just radiantheating with fan, were tested to reduce the drying time for this one-part epoxy. Use of this ink has been discontinued due to relatively slow drying.

A water-soluble ink dries fast, has low outgassing, is reusable, but prints in somewhat thin layers and has not had as good adhesion as the epoxy type inks. In addition, screens needed for the water-soluble inks have been more difficult to make, but screen making techniques have improved with practice. Ink additives have greatly improved adhesion. Screen cleaning without cleaning solution (used with water) remains a problem.

Two different thicknesses of water-based capillary emulsion have been obtained and applied to screens. Neither passed acceptable with the water based ink. A liquid based emulsion applied with a scoop has been successfully used.

\section{Single print experiments}

The experimental run using a single insulator ink print, with a variety of laser beam powers used to cut an open in the TCO coating, has been analyzed. A typical single print line thickness is around $20 \mathrm{\mu m}(0.8 \mathrm{mil})$, depending on viscosity of ink printed. A variety of laser beam powers ranging from $0.25 \mathrm{~W}$ to $1.2 \mathrm{~W} @ 5 \mathrm{kHz}$ pulse frequency was tried. The range of $0.4 \mathrm{~W}$ to $0.8 \mathrm{~W}$ can produce opens in the TCO layer without totally cutting through the ink and metalization. Typically, a value in the $0.6-0.7 \mathrm{~W}$ range is acceptable. Efforts are currently underway to do additional trial runs to reproduce these results. 


\subsection{Task 8: Busbar Attachment and Web Cutting Automation}

Phase II Task 8 efforts were aimed at automating the final process steps of busbar attachment and web cutting. Commercial equipment or equivalent designs were evaluated. Development of one machine with the ability to perform these two steps with one alignment process was given high priority. This task was expected to produce the design and implementation of an automated system for busbar attachment and cutting modules off the roll.

Task efforts were to complete vendor survey of equipment for attaching busbars to the roll web and for cutting off module lengths for encapsulation; complete the design for an automated busbar and sheeting machine; and complete the order placement for an automated busbar sheeting machine/components.

After reviewing systems on the market for attaching busbars to the web, two system types were identified. The first is for use with Dupont Tefzel and EVA. This type of system would use robotics to assemble the module. There were multiple vendors available with robotic arms to fit this function. The robotic arm would be able to apply both the conductive adhesive (which holds the busbar in place) and the busbar to the web. Many vendors specialize in making custom heads for robotic arms. This procedure means that the material to be processed would have to be done sheet by sheet where the web would be cut and placed in a jig or fixture. The robotic assembly would then follow, placing down the conductive adhesive and busbar. After the robotic assembly was done the operator would change out the fixture with another one and have the robotic assembly start all over again. The operator could complete the module encapsulation by placing the cosmetic tape over the busbars, then sheet the module with a Tefzel/EVA overlaminate. The module would then be removed from the fixture and laminated in a conventional vacuum laminator. These steps would complete the module assembly.

It was determined that accomplishing this task through a "roll to roll" process would be impossible due to the physical connection between the busbar and the device material. When the material was rolled up, the bus would fall or break off the web before lamination. An additional problem was getting around interconnecting the modules on the web, i.e., module to module. There would also be the problem of making the $1 / 2$ " weather seal that is required for individual modules to pass the twenty year lifetime testing.

The second system under evaluation is a taping system where conductive copper (cu) tape is placed on the contact pads. Most of the taping industry is geared around cutting and feeding a piece of tape so an operator can pick off that piece of tape and place it where it needs to be. Another part of the industry is geared around taping large rigid structures as in the box industry. However, one manufacturer was found that has a taping system which can do sheet taping. Their machine can place strips of tape lengthwise across a thin piece of material. As a self contained unit, it is designed to do sheets of material one at a time. The heads for this unit can be purchased individually for alternative uses. With a system like this it is possible to place busbar material across the web using a roll-to-roll method. If this system is used with an alternative encapsulation (other than Tefzel) like a TSA and UV stabilized polyester then it can be roll laminated. 
Another endeavor during this period was to establish a vendor survey of equipment available for cutting off module sections for encapsulation. There are many manufacturers that make dies and presses for cutting off lengths of material for encapsulation. Some of the die types include rotor die, clicker die, and die cutting. This industry is geared around cutting raw material in multiple forms then processing the cut assemblies while still held in the web. Die cutting photovoltaic material requires precision cutting. The equipment has to be able to hit the lines within one millimeter of accuracy. One manufacturer was found that offers precision placement and die cutting in a package that can process our material. This system, incorporating optical alignment with precision die cutting, is fairly expensive costing between $\$ 100,000$ to 250,000 . The other two methods for cutting out the material were "clicker die" and "rotary die" systems Both offer high speed and throughput, but precision is not possible without perfect cell to cell fabrication. Any variation in the distance between modules could result cutting the wrong area. Both of these systems are based on simultaneous cutting and advancing the material. Conclusion: .die.cutting dies offer the most flexibility, accuracy, and throughput for processing photovoltaic modules.

The final design for both the automated busbar attachment system and the sheeting/die cutting system consists of a base system with the features described below:

The supply and take up mandrels will be compatible with the ITFT A-Si production line. They will be used for solar material handling through either system. A torque motor/controller will be on the take up mandrel and a stepper motor/encoder will be on the supply mandrel. These two systems will provide precision control of the web in the $\mathrm{X}$ direction, down the web.

The $\mathrm{Y}$ direction of the web is controlled by a linear screw type drive system that the frame for the supply and take up mandrel are attached to. It consists of a carriage plate, which supports both the supply and return rolls, mounted to four pillow block bearings. The bearings ride on two shafts with the shafts mounted to a base plate by six base supports. A short Acme screw will drive the carriage plate along the $\mathrm{Y}$ axis and a computer controlled stepper motor will drive the Acme screw along the $Y$ axis.

The rotational or Theta axis adjustment will be done manually via a screw rod between the web system and the process equipment. Automation is not necessary for the rotational axis. Once the carriage plate is aligned along the Theta axis of the process equipment there should not be a need to realign the system from run to run.

A controller for alignment and cycling in either the sheeting/die cutting or the busbar taping operation will probably be done by a computer with a PC 23 system or some similar control mechanism.

For the busbar attachment system, the base system will be configured on a platen that has taping heads for placing the conductive bus on the web. The taping heads have to be placed down on the web where they must travel across it placing the conductive busbar. A vacuum hold-down plate will used to assure that there is no web movement during tape application. At the end of the stroke, the heads will cut the tape and raise up off the web. The lift-off of the heads will be accomplished at the end of each stroke by air cylinders. This will enable the heads to return to the 
beginning of the stroke without touching the web. Sensors for the lift-up of the tape heads are mounted at each end of the tape head stroke. These sensors will be adjustable to accommodate the different lengths of tape to be applied. The fully adjustable sensors will be mounted on a rail. After tape placement the web will be advanced to the next busbar placement location. During the web advancement the taping heads will return to their original position. The process will then be repeated. Please refer to Figure 3 which illustrates this system.

For the sheeting/die cutting system, the base system will be used. It will be mounted around the press where the take-off height of the web will be slightly higher than the base of the die. The process is similar to the busbar system: the web will be aligned relative to the press and once the web is aligned the press will cycle and the PV material will be cut to specification. Optical sensors will be used to verify that the PV modules have been removed from the die before there is another stroke of the press. The press will proceed to the top of its stroke then the web will be air kissed off the die bottom where it can be advanced to the next frame, where the process can be repeated. Please refer to Figure 4 which illustrates this system.

The PC controller was identified. However, a minor problem was encountered with the selected controller. The single axis controller/driver cannot run a stepper motor while receiving feedback from an idler roller encoder. The controller is designed to drive the stepper motor a fixed distance for a set input. If an external encoder is used to measure actual web distance via an idle roller and the command is set to move the web a fixed distance based on that encoder, the following occurs:

-As the drive motor is on the take-up roller of the machine, the diameter increases with each revolution of material around the roll, and -the number of pulses required to move the web the same distance will decrease throughout the run.

Therefore the single axis controller/driver will not perform this function.

A 1-4 axis controller with greater versatility has been evaluated to handle this problem and perform all other functions required for the automated busbar sheeting machine.

A die for sheeting/cutting a section of material was received. The first prototype die processes Iowa Thin Film's $2 \mathrm{~cm} 5$ cell $27 \mathrm{~mm}$ wide material. The die will cut 16 mini modules in one stroke. Other dies for processing different module sizes will be ordered later once the completed machine has proven it's functionality.

\subsection{Task 9: Reduction in Encapsulant and Module Assembly Costs}

Phase II Task 9 efforts were aimed at the establishment of a roll-based laminating process to decrease module assembly labor costs. A low cost top transparent encapsulant was sought to replace the single layer of high cost flouropolymer. Evaluation of encapsulant performance included encapsulant effects on module performance, adequacy of edge sealing and stability against temperature cycling. Multiple layers of lower cost transparent polymers as a replacement 

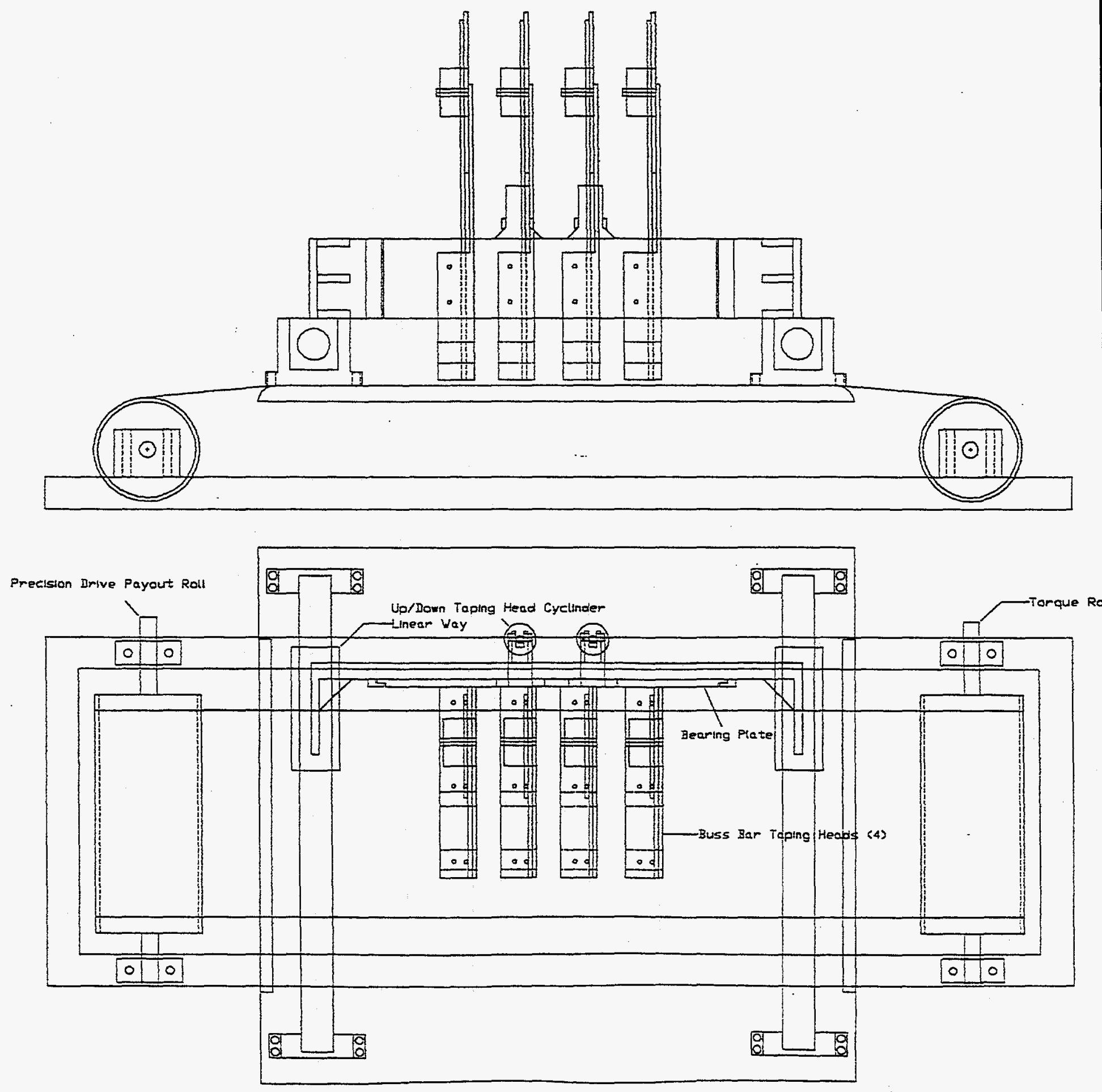

Figure 3. Busbar attachment system 


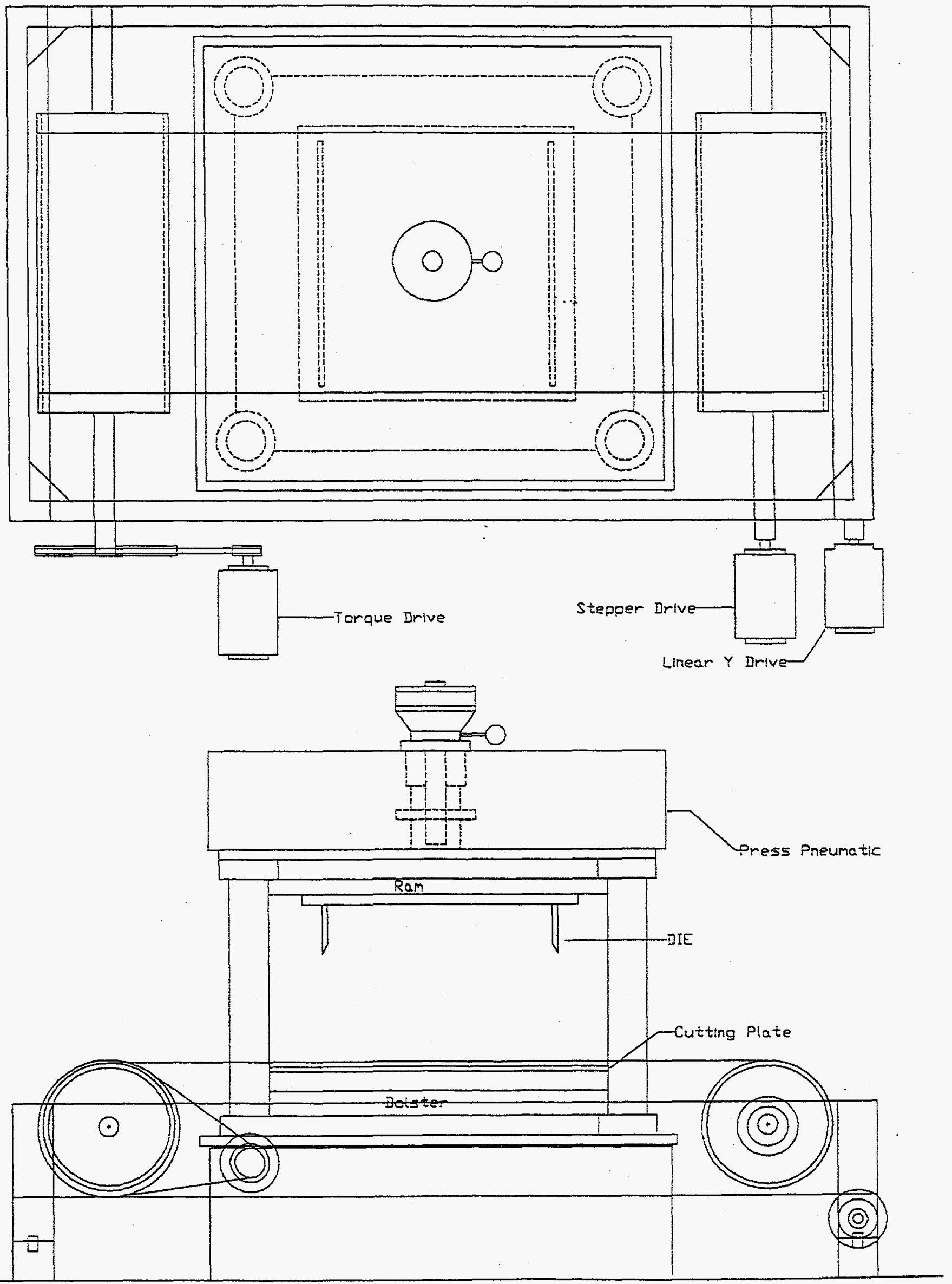

Figure 4. Sheeting/die cutting system 
for the high cost material, Tefzel, would also investigated. Candidate layers in the stack configuration were to be selected according to specific requirements including abrasion resistance, UV light resistance, water barrier ability, and adhesion characteristics.

This portion of the task was expected to provide a lower cost encapsulant for ITF modules resulting in a $13 \%$ reduction in baseline $\$ / W$ cost of module manufacturing in this area. The results from this task will be implemented and completed in Task 14.

Specific Task efforts were to complete survey of available polymer films and vendors; deliver a representative, $\geq 6.0 \%$ efficient, $1-\mathrm{ft}^{2}$ ITF module using $\mathrm{PVMaT}$ process technology; complete analysis including process times and cost of the step-by-step fabrication of $1 \mathrm{ft}^{2}$ ITF modules using process technology developed under PVMaT; demonstrate operation of roll based laminating machine; complete in-house testing of potential laminator layer materials; deliver nine representative state-of-the-art, fully encapsulated modules for qualification and long-term lifetesting at NREL; complete selection of individual laminate layers; deliver two representative, $1 \mathrm{ft}^{2}$ ITF modules demonstrating the PVMaT developed encapsulation by the roll based lamination process; deliver two representative, $\geq 6.5 \%$ efficient, $1-\mathrm{ft}^{2}$ ITF modules using PVMaT process technology; and complete analysis including process times and cost of the step-by-step fabrication of $1 \mathrm{ft}^{2}$ ITF modules using process technology developed under PVMaT.

\section{Survey of available polymer films and vendors}

The listing shown on Table 1 compares cost, optical transmission/reflection, durability, UV resistance, cohesion, tear resistance, and salt water corrosion results for laminates tested. The cost information was based on a specified quantity quote. Actual production costs will probably go down once annual usage has been estimated. The quantities of each material varied for these estimates.

Measurements for optical transmission/reflection were taken on a Perkinlmer Lambda 9 Spectrophotometer, the transmission and reflection were recorded as a percent of 100 . Reflection numbers included both reflection and absorption percentages. Materials where numbers are not given were not tested on the spectrophotometer because of failures in other areas. Durability and tear resistance were based on physical testing of the material, tear testing was done down grain and across grain were applicable. In most cases the materials that tore down grain did not tear across grain. UV resistance was based on the manufacturers' numbers, not actual testing done by Iowa Thin Film. Polymer laminates that pass testing will be sent to NREL for accelerated UV testing. Cohesion was based on actual modules that were laminated, the modules were examined for air pockets along the edges and the numbers were based on this analysis. Salt water testing was a pass/no pass situation, testing results were not in yet for the other laminates listed at the time of this report.

A thirty foot section of non functional PV modules were taped together and rolled up by hand on a standard a-Si aluminum mandrel. This thirty foot section was then mounted on the supply or "pay out" mandrel. The encapsulant was threaded through the appropriate rollers and taped to the take-up mandrel on the back of the machine. The take-up mandrel was set for maximum 
Table 1. Comparison of film laminates.

\begin{tabular}{|c|c|c|c|c|c|c|c|c|}
\hline & & Optical Clarity & & & & & Tear & \\
\hline Tefzel(4) & $2 \$ / \mathrm{ft}^{\wedge} 2$ & $95 \%$ & $3 \%$ & 10 & 10 & $n / a$ & 10 & 10 \\
\hline Dartek(4) & $.03 \$ / \mathrm{ft}^{\wedge} 2$ & $88 \%$ & $6 \%$ & 5 & 1 & $n / a$ & 6 & \\
\hline $7735 f 1(2)$ & $.15 \$ / \mathrm{ft}^{\wedge} 2$ & $90 \%$ & & 5 & 9 & 8 & 1 & \\
\hline $7747 f(2)$ & $.17 \$ \mathrm{ft}^{\wedge} 2$ & $90 \%$ & & 7 & & 8 & 8 & \\
\hline UVPOLY12(3) & $.02 \$ / \mathrm{t}^{\wedge} 2$ & $83 \%$ & $6-7 \%$ & 9 & 9 & 8 & 10 & 10 \\
\hline UVPOLY32(3) & $.05 \$ / \mathrm{At}^{\wedge} 2$ & $83 \%$ & $6-7 \%$ & 9 & 9 & 10 & 10 & 10 \\
\hline $7731 \mathrm{fl}$ & $.15 \$ / \mathrm{ft}^{\wedge 2}$ & & & 9 & 6 & 7 & 8 & \\
\hline 7730 fl & $.09 \$ / \mathrm{ft}^{\wedge} 2$ & & & 5 & 9 & 7 & 1) & \\
\hline $7741 \mathrm{fl}$ & $.18 \$ / \mathrm{ft}^{\wedge} 2$ & & & 7 & & 4 & 8 & \\
\hline Tedlar Clear & $1.0 \$ / \mathrm{t}^{\wedge} 2$ & & & 6 & & 8 & 7 & \\
\hline
\end{tabular}

(1) average from $400 \mathrm{~nm}-1200 \mathrm{~nm}$

(2) laminated on quartz microscope slide for optical tests

(3) laminated to it's self for optical tests

(4) tested as a film no adhesive

(5) Total loss Reflection + absorption

(6) Durability/UV resistance/Cohesion/Tear Resistanc/ and Salt Water Corosion are scaled from 1-10 
torque. The preheaters were turned on to their pre-set temperature and allowed to warm up. Once the preheaters reached the optimum temperature, the drive for the rollers was turned on and the solar modules were fed into the laminator. The lamination ran all thirty feet before the drive system was tuned off. It should be noted that because the solar modules were hand rolled onto the a-Si mandrel they were not perfectly straight. As a result, at approximately 26 feet from one end of the run of modules there is a wrinkle approximately 2-3 feet long. Machine alignment of a run of modules will result in a "true" attachment of the modules to the mandrel and will eliminate wrinkles and/or binding of the solar modules in the laminator during encapsulation.

\subsubsection{Complete in-house testing of potential laminator layer materials}

The majority of the encapsulants tested to date are listed below in Table 2 as a "pass" or "not pass" for the following in house tests: salt water corrosion, $80^{\circ} \mathrm{C}$ soak, and thermal cycling $\left(-40^{\circ} \mathrm{C}\right.$ to $\left.80^{\circ} \mathrm{C}\right)$. UV soak and optical transmission tests for the encapsulants that passed all three tests will be presented following Table 2 .

Table 2. Results of in-house testing. (Conditions: pass/fail)

\begin{tabular}{|c|c|c|c|}
\hline 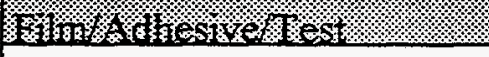 & 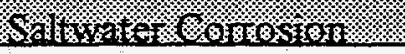 & 8080.56214 & 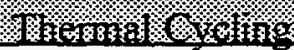 \\
\hline Tefzel@/EVA & pass & pass & pass \\
\hline Tefzel@/Silicon PSA & pass & pass & pass \\
\hline Tefzel@/Acrylic PSA & fail penetrated module & pass & fail delaminated \\
\hline Dartek@/Eva & pass & pass & pass \\
\hline Dartek@/silicone PSA & pass & pass & pass \\
\hline Dartek@/Acrylic PSA & fail penetrated module & pass & pass \\
\hline Acalarß/Acrylic PSA & failed delaminated & fail cracked & fail cracked \\
\hline Polyester/Polyethylene \#12 & pass & pass & pass \\
\hline Polyester/Polyethylene \#23 & pass & pass & pass \\
\hline Polyester/Polyethylene \#28 & pass & pass & pass \\
\hline Tedlar@/EVA & pass & pass & pass \\
\hline Tedlar@/Silicone PSA & fail delaminated & pass & pass \\
\hline Tedlar(\&/Acrylic PSA & fail delaminated & pass & fail delaminated \\
\hline
\end{tabular}


The following modules were not sent to NREL for UV exposure because of the time the test took and the unavailability of films that were wide enough at the time the modules were due to be sent in. Tedlar $\& /$ EVA and Tefzel $B /$ silicone PSA were not sent because the sample films were not wide enough for the $\mathrm{ft}^{2}$ modules that NREL requested for testing. Polyester/Polyethylene \#23 wasn't sent because two previous candidates had already been sent in: \#12 and \#28. Tefzel\&/EVA has already passed IEEE module qualification sequence Standard 1262.

Dartek®/EVA wasn't sent in for UV testing because the initial Dartek® module failed the UV exposure testing. Tedlarß/EVA and Tefzelß/silicone PSA were sent to NREL for UV testing as soon as sample encapsulants are received. Finally, any new encapsulants that pass the three inhouse tests will be submitted to NREL.

Three $1 \mathrm{ft}^{2}$ single junction a-Si modules with candidate lamination samples, were sent to NREL for UV exposure testing. The intention of this experiment was to see how these experimental encapsulants would handle the UV exposure level as specified in the IEEE sequence Standard 1262.

The three encapsulated modules were exposed for 35.1 days under a UV irradiance of $17.8 \mathrm{~W} / \mathrm{m}^{2}$. This testing brings the total exposure to $54 \mathrm{MJ} / \mathrm{m}^{2}$, and an approximate lifetime UV exposure of 10 years under normal irradiance. Figures 5 and 6, presenting data supplied by NREL, show preexposure I-V measurements (Fig. 5) and post-exposure I-V measurements (Fig. 6). It should be noted that the modules sent to NREL for testing were not "state of the art" modules but modules typically with a 4-4.5 percent efficiency. After examining the results of the optical transmission tests calculated by NREL and shown in Table 3, it can be seen that the majority of the losses (approximately 10\%) in Pmax, were due to the Staebler-Wronski effect. Sample "F24" showed the greatest overall losses. This was due to yellowing of the non UV stabilized nylon film that was used in the encapsulant.

Table 3. Relative changes in I-V parameters (\%). As tested at NREL.

\begin{tabular}{|c|c|c|c|c|}
\hline (3) & $x$ & / & $1 \%$ & P. \\
\hline X) & -0.7 & -5.9 & -2.1 & -8.7 \\
\hline Vy & -2.1 & -4.0 & -8.1 & -14.6 \\
\hline 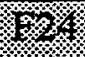 & -0.7 & -12.2 & -4.7 & -18.3 \\
\hline
\end{tabular}

After ITF received the modules that had been UV soaked by C.R. Osterwald at NREL, optical transmission data was taken on the encapsulants. Samples "F22" and "F23" were polyester/ polyethylene encapsulants, with different thicknesses of film and adhesive and sample "F24" was a nylon/silicone encapsulant. Data taken above 600nm on "F22" had too much "noise" to get an accurate number for the per cent change from pre UV soaked encapsulant and post UV soaked material. Data from the encapsulants that were tested are shown in Table 2. 


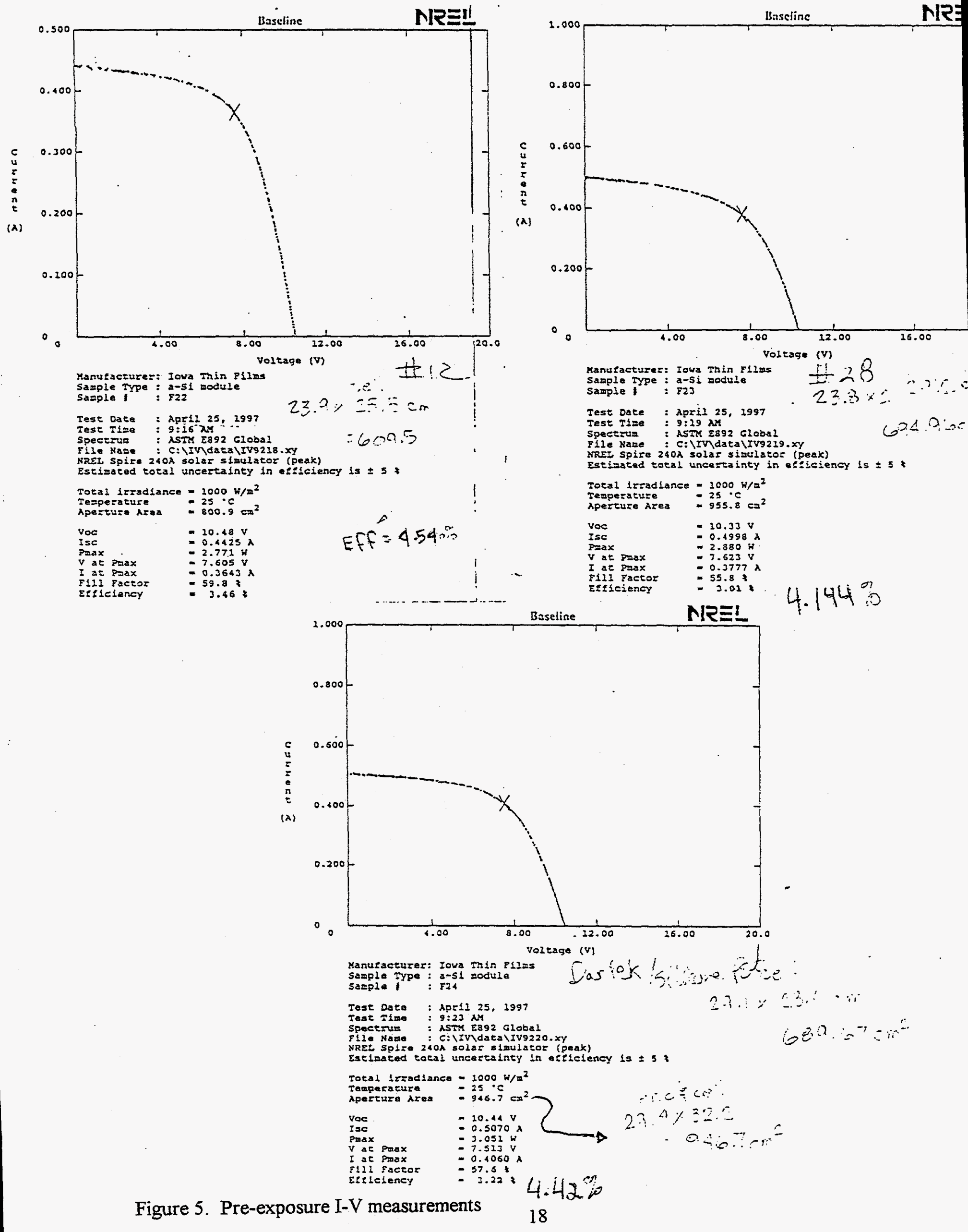


Table 4 presents data on the differences in per cent change in the light transmission of the pre UV soaked and post UV soaked material.

Table 4. Relative changes in light transmission shown by per cent change. (Tested at ITFT)

\begin{tabular}{|c|c|c|c|c|c|c|c|c|}
\hline 48 & (4) & 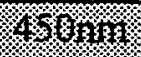 & $8,8(4)$ & S364) & 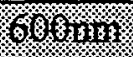 & 686941: & K6ysing & 480818. \\
\hline F22 & -13.0 & -0.7 & 0.0 & 0.0 & -.--- & --.---- & --.-- & ------ \\
\hline F23 & -16.0 & -2.4 & -1.7 & +0.5 & +0.6 & +1.1 & +1.9 & +1.1 \\
\hline F24 & -38.4 & -18.7 & -8.8 & -3.8 & -1.5 & -0.8 & -0.8 & -0.4 \\
\hline
\end{tabular}

In the polyester/polyethylene encapsulated modules the greatest losses occurred between $350 \mathrm{~nm}$ and $450 \mathrm{~nm}$. Considering the amount of light energy available at frequencies below $400 \mathrm{~nm}$ the losses of $13-16 \%$ seems quite negligible. It was interesting to see that there was an increase in the percentage of light transmitted from $550 \mathrm{~nm}$ to the end of the visible light spectrum at $750 \mathrm{~nm}$. "F24" seemed to suffer the greatest loses in light transmittance throughout the entire visible spectrum. Part of this was due to the fact that the encapsulating film used was a non-UV stabilized nyion film. Again the majority of the losses occurred between $350 \mathrm{~nm}$ and $500 \mathrm{~nm}$ in the lower $1 / 3$ of the light spectrum. Table 4 only shows percent change in the visible spectrum.

Figures 7,8 , and 9 show results from samples cut from the trimmed material (pre UV soaked) and from the weather seal ( $1 / 2$ " border) post UV soaked material. The plots shown in these three figures were measured from $200 \mathrm{~nm}$ to $1000 \mathrm{~nm}$. Data on all three samples shows very little difference in pre- and post-exposure above $750 \mathrm{~nm}$ and below $250 \mathrm{~nm}$. In all three figures, line $A$ is pre-UV exposure and line $B$ is post-UV exposure.

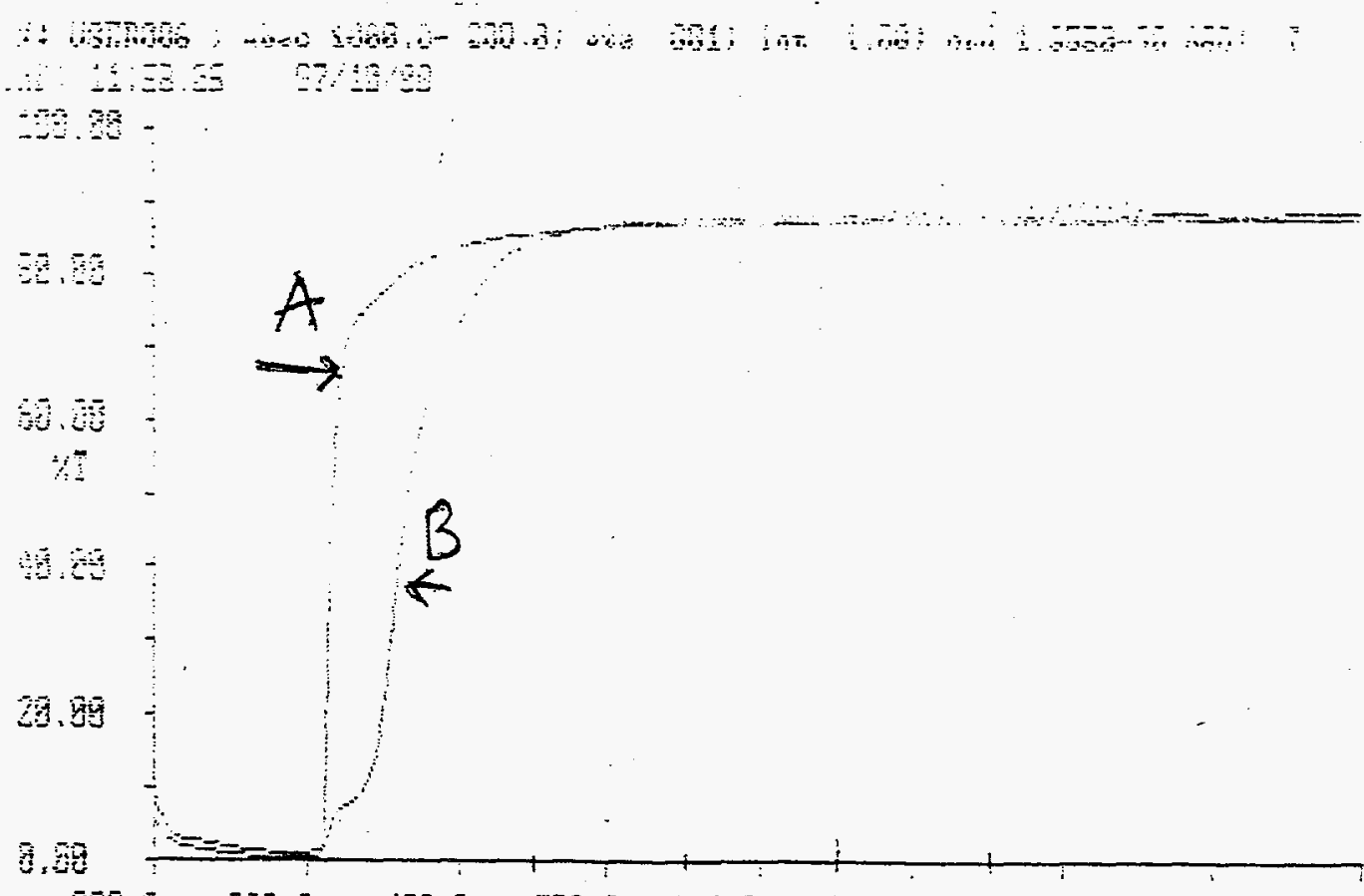

$70 . \overline{8}$ 390.

Figure 7. F22: Pre-UV exposure (A) and post-UV exposure (B) compared 


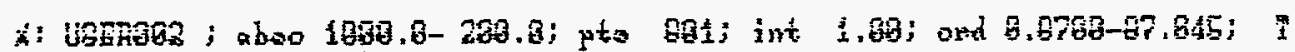
inf : $14: 39: 11 \quad 37 / 43 / 98$

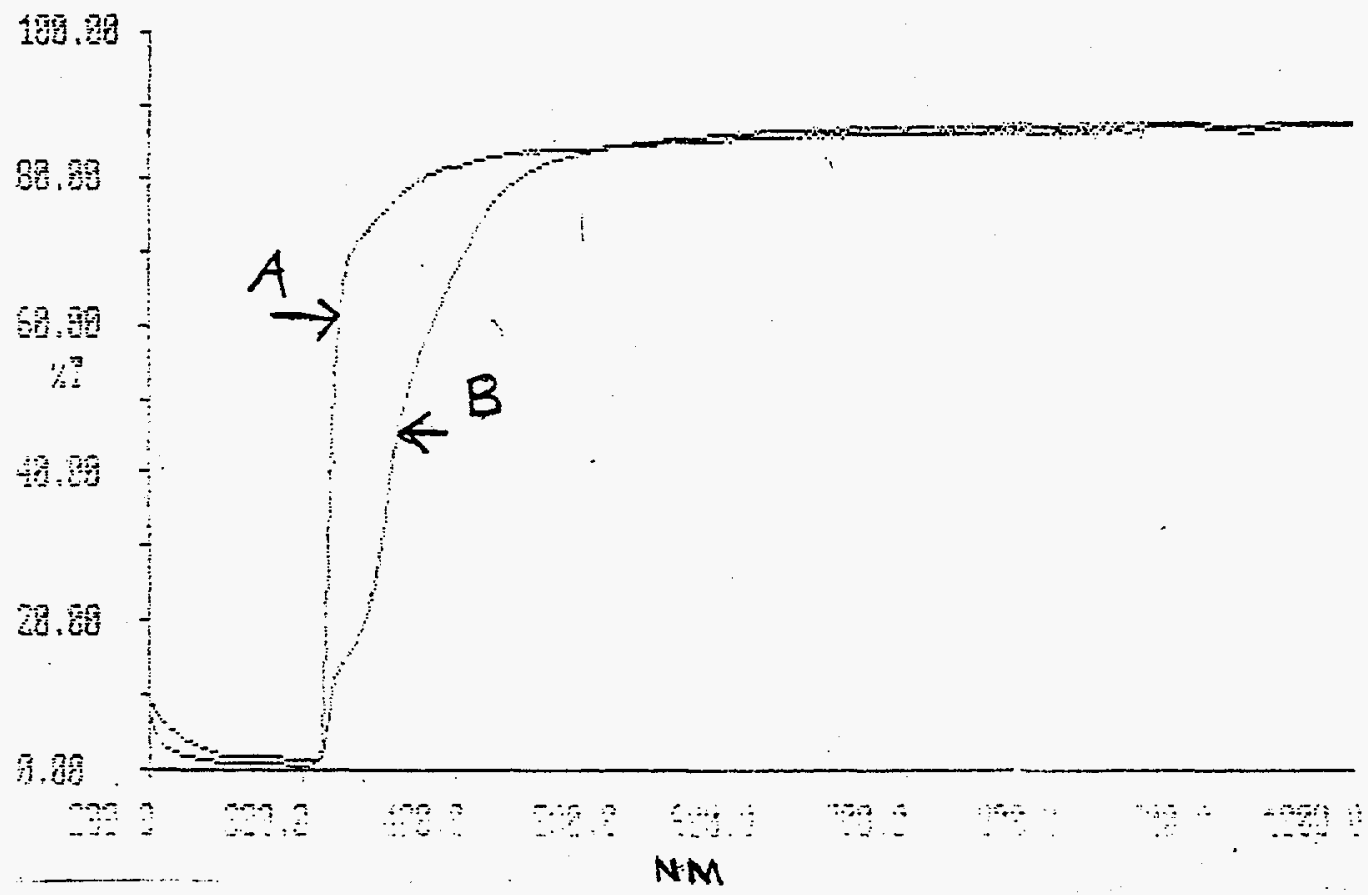

Figure 8. F23: Pre-UV exposure (A) and post-UV exposure (B) compared

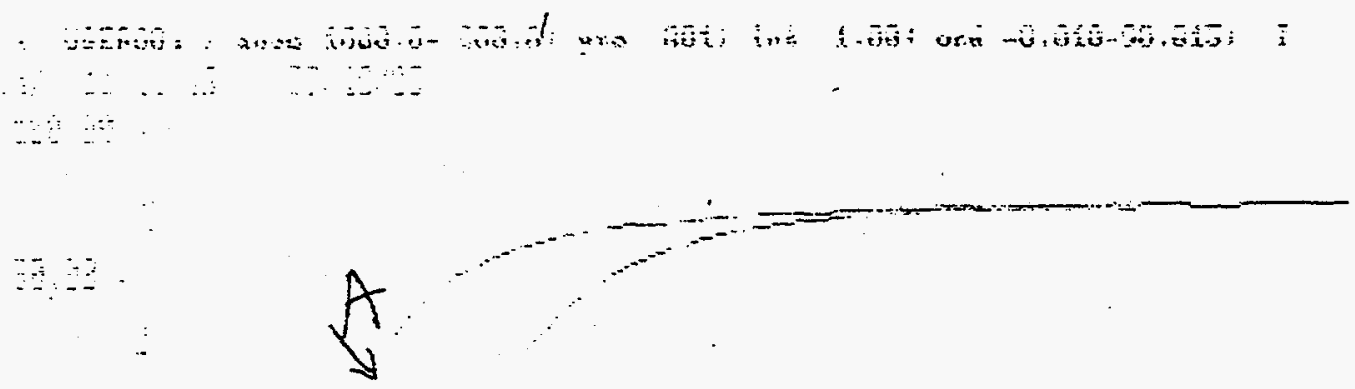

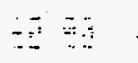

$\stackrel{B}{\longleftarrow}$

$\therefore \therefore$

3

i. 
The polyester/polyethylene encapsulants look good for a medium lifetime product (up to 10 years). Further long term testing will be done to insure the durability of these encapsulants. The Tedlar/EVA and Tefzel/Silicon PSA encapsulants will be sent for UV exposure at NREL as soon as appropriate sample material is received from the manufacturers.

\section{Selection of individual laminate lavers}

Table 5 presents a list of individual laminate layers, the applicable manufacturing process, relative cost, and overall durability.

Table 5. Individual laminate layers, applicable manufacturing process, relative cost, and overall durability.

\begin{tabular}{|c|c|c|c|c|c|c|c|}
\hline (6) & Wofinesing & (6) & $x_{1} f_{1}, y$ & 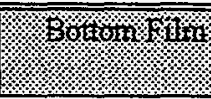 & 4161 & 4 & matis \\
\hline$\# 1$ ETFE & EVA & a-Si/poly & EVA & ETFE & Vacuum & 10 & 10 \\
\hline \#2 EIFE & EVA & a-Si/poly & EVA & Nylon & Vacuum & 8 & 8 \\
\hline$\# 3$ Nylon & EVA & a-Si/poly & EVA & Nylon & Vacuum & 5 & 4 \\
\hline \#4 Polyester & EVA & a-Si/poly & $\overline{E V A}$ & Polyester & Roll to Roll & 2 & 1 \\
\hline \#5 Polyester $2 \mathrm{mil}$ & Polyethylene 8mil & a-Si/poly & Polyethylene 8mil & Polyester 2mil & Roll to Roll & 5 & 7 \\
\hline \#6 Polyester $2 \mathrm{mil}$ & Polyethylene 3mil & a-Si/poly & Polyethylene 3mil & Polyester 2mil & Roll to Roll & 2 & 5 \\
\hline$\# 7$ Polyester 1mil & Polyethylene $2 \mathrm{mil}$ & a-Si/poly & Polyethylene 2mil & Polyester Imil & Roll to Roll & $\mathrm{l}$ & 3 \\
\hline 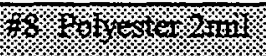 & Polyethylene 8mil & a-Si/poly & Polyethylene 3mil & Polyester $2 \mathrm{mil}$ & Roll to Roll & 3.5 & 6 \\
\hline$\# 9$ Polyester $2 \mathrm{mil}$ & Polyethylene $8 \mathrm{mil}$ & a-Si/poly & Polyethylene $2 \mathrm{mil}$ & Polyester Imil & Roll to Roll & 3 & 4 \\
\hline$\# 10$ Polyester $2 \mathrm{mil}$ & Polyethylene 3mil & a-Si/poly & Polyethylene 2mil & Polyester Imil & Roll to Roll & 1.5 & 3 \\
\hline
\end{tabular}

The manufacturing (MFG.) processes shown above are vacuum and roll to roll lamination. The roll to roll lamination process is considerably more manufacturable than vacuum lamination. In a production rate comparison, vacuum lamination throughput is run a few feet for a few minutes whereas roll to roll lamination is run on the order of feet/second. The cost of the material was based on the most expensive rated above as " 10 " and the least expensive rated above as "1:" The durability of the encapsulant was based on a subjective method with various testing procedures supporting the above ratings. The best overall appears to be $\# 8$, the Polyester $2 \mathrm{mil} /$ polyethylene $8 \mathrm{mil} / \mathrm{a}-\mathrm{Si}$ / poly module / polyethylene $3 \mathrm{mil} /$ polyester 2 mil using the roll to roll lamination method. While the relative cost is extremely low the durability is excellent and the lamination process is very manufacturable. 


\subsection{CONCLUSIONS AND FUTURE WORK}

Work done during Phase II, year 2, aimed at achieving the overall program goal of developing the most cost effective PV manufacturing process possible, resulted in significant progress being made in reducing the manufacturing costs of our thin film photovoltaics. Throughput was improved on the $\mathrm{ZnO}$ deposition system, the laser scriber, and the printer. Registration accuracy on the printer was improved by almost an order of magnitude. A new roll-to-roll lamination process was implemented which increases lamination rates 12 fold. Low cost encapsulants were evaluated and a product chosen for initial release in 5 year lifetime applications. In addition, important development was accomplished on module assembly automation. Overall cost reduction to date for Phases I and II has been $49 \%$ 


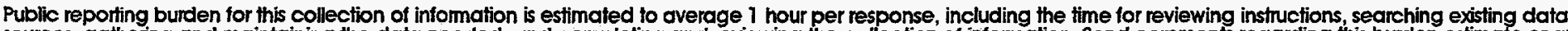

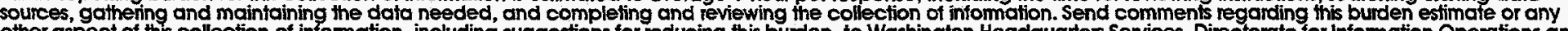

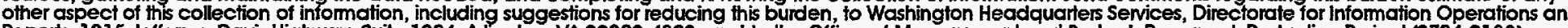

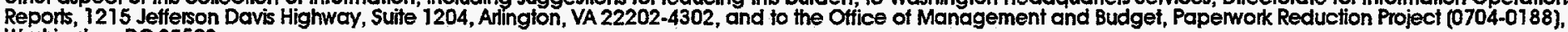
Washington, DC 20503

\begin{tabular}{|l|l|l}
\hline 1. AGENCY USE ONLY (Leave blank) & $\begin{array}{c}\text { 2. REPORT DATE } \\
\text { August 1998 }\end{array}$ & $\begin{array}{l}\text { 3. REPORT TYPE AND DATES COVERED } \\
\text { Annual Technical Progress Report, 5 July 1996-31 December 1997 }\end{array}$
\end{tabular}

4. TILE AND SUBTITLE

Photovoltaic Manufacturing Technology Monolithic Amorphous Silicon Modules on Continuous Polymer Substrates, Annual Technical Progress Report, 5 July 1996-31 December 1997

\section{AUTHOR(S)}

F. Jeffrey

7. PERFORMING ORGANIZATION NAME(S) AND ADDRESS(ES)

Iowa Thin Film Technologies, Inc.

2501 North Loop Dr.

ISU Research Park

Ames, IA 50010

9. SPONSORING/MONITORING AGENCY NAME(S) AND ADDRESS(ES)

National Renewable Energy Laboratory

1617 Cole Blvd.

Golden, CO 80401-3393

\section{FUNDING NUMBERS}

C: $2 A F-5-14271-4$

TA: PV805101

8. PERFORMING ORGANIZATION REPORT NUMBER

\section{SUPPLEMENTARY NOTES}

NREL Technical Monitor: R. Mitchell

120. DISIRIBUTIONAAVALABILITY STATEMENT

National Technical Information Service

12b. DISTRIBUTION CODE

U.S. Department of Commerce

5285 Port Royal Road

Springfield, VA 22161

\section{ABSTRACT (Maximum 200 words)}

Iowa Thin Film Technologies, Inc.'s goal is to develop the most cost-effective photovoltaic manufacturing process possible. To this end, we have chosen a roll-based manufacturing process with continuous deposition and monolithic integration. Work under this program is designed to meet this goal by improving manufacturing throughput and performance of the manufactured devices. Progress made during Phase II of this program includes the following: a new single-pass tandem deposition machine was brought online that allows greatly increased and improved throughput for rolls of tandem material; the TCO deposition process was improved, resulting in an increase in throughput by $20 \%$; a new alignment method was implemented on the printing process that improves throughput six-fold while improving alignment from $100 \mu \mathrm{m}$ to $10 \mu \mathrm{m}$; a roll-based lamination procedure was developed and implemented on selected products that improves throughput from $20 \mathrm{sq}$. $\mathrm{fth}$ to $240 \mathrm{sq}$. $\mathrm{fth}$; and we evaluated a wide range of lower-cost encapsulants and selected a promising material to be introduced in 5-year-lifetime type products. The sum of these improvements brings the cost reduction resulting from this program to $49 \%$.

\section{SUBJECT TERMS}

15. NUMBER OF PAGES

photovoltaics ; Photovoltaic Manufacturing Technology; PVMaT; monolithic amorphous silicon; continuous polymer substrates; roll-based manufacturing

$$
29
$$

16. PRICE CODE

17. SECURITY CLASSIFICAIION OF REPORT Unclassified
18. SECURITY CLASSIFICAIION OF THIS PAGE Unclassified
19. SECURITY CLASSIFICATION OF ABSTRACT Unclassified
20. LIMITATION OF ABSTRACT

UL 